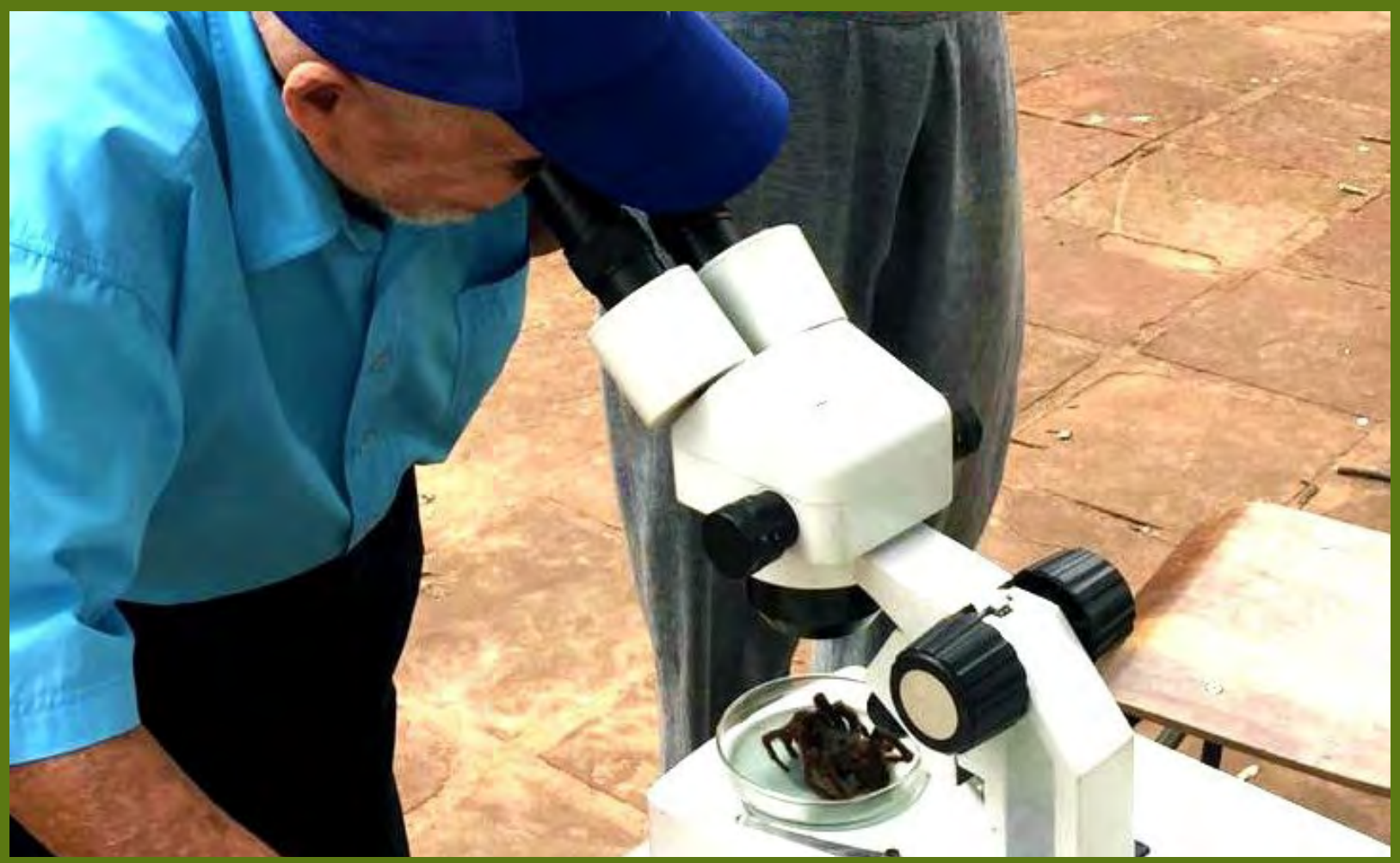

\title{
Ciência na rua: ação extensionista em Jacarezinho-PR
}

Maiara Risse de Camargo - maiararisse@gmail.com ${ }^{1}$

Cibele Bender Raio - cibele.raio@gmail.com ${ }^{2}$

\section{RESUMO}

Este artigo descreve as atividades extensionistas realizadas durante o evento "Ciência na Rua", organizado por acadêmicos de Ciências Biológicas, na Universidade Estadual do Norte do Paraná (UENP), campus Jacarezinho. 0 evento foi realizado em praça pública, próximo à universidade. Durante o acontecimento, foram selecionados materiais da coleção zoológica do curso de graduação para a exibição. Foram realizados, ainda, observação de animais em microscópio estereoscópico, com o objetivo de observar estruturas dos exemplares expostos; promovidos jogos didáticos, para que os participantes tivessem acesso à termos biológicos; organizadas oficinas de desenhos, lideradas por estudantes com experiência em desenhos científicos; e apresentados os processos de compostagem, a partir de explicações de como o processo de decomposição em uma composteira doméstica.

PALAVRAS-CHAVE: desenvolvimento sustentável; divulgação científica; educação não formal.

1 Acadêmica do Curso de Licenciatura em Ciências Biológicas da Universidade Estadual do Norte do Paraná, bolsista da Fundação Araucária (PIBIS).

2 Docente Colaboradora do Curso de Licenciatura em Ciências Biológicas da Universidade Estadual do Norte do Paraná. 


\title{
Science in the street: an Outreach Action in Jacarezinho - PR
}

\begin{abstract}
This paper describes some outreach activities conducted during the event "Science in the Street", that was organized by academics of Biological Sciences at Universidade do Norte do Paraná (UENP), Jacarezinho campus. The event was held in a public square near the university, where the following activities took place: materials were selected from the zoological collection of the undergraduate course for the exhibition; animal observation was provided, where participants could see structures of the exposed specimens through a stereoscopic microscope; educational games were made available, so that participants hadaccess to biological terms; drawing workshops were organized, which were led by students with experience in scientific drawing. Also, composting processes were presented by way of explanations about the decomposition process in a domestic composter.
\end{abstract}

KEYWORDS: sustainable development; scientific dissemination; non-formal education.

\section{RELATO DE EXPERIÊNCIA}

0 ensino superior, de acordo com o art. 43 da Lei de Diretrizes e Bases da Educação Nacional (Lei no 9.394, de 20 de dezembro de 1996), tem como uma de suas finalidades a promoção de atividades extensionistas para disseminação de conquistas e benefícios garantidos pela ciência, criação cultural e tecnológica, desenvolvidas nas universidades para com a população (BRASIL, 1996).

Complementarmente, as Diretrizes para a Extensão na Educação Superior Brasileira (Resolução nº 7 , de 18 de dezembro de 2018) estabelece, em seu art. $3^{\circ}$, que a extensão pode ser definida como atividade integradora dos processos interdisciplinares, científicos, culturais, político educacional, entre outros (BRASIL, 2018), ou seja, as ações de extensão operam diretamente na comunicação entre sociedade e ensino por meio do compartilhamento do conhecimento científico. Além disso, essas ações contribuem significativamente para a formação integral do estudante (FORPROEX, 2007).

Com base nesse contexto, é possível compreender que a extensão se caracteriza como instrumento relevante para a democratização dos conhecimentos científicos. Por sua natureza, os trabalhos de extensão têm como objetivo compartilhar o conhecimento produzido e adquirido nas universidades, por meio do ensino e da pesquisa, com a comunidade externa. Dessa forma, eventos que promovem a divulgação científica disseminam conhecimentos acadêmicos e contribuem para a formação estudantil.

0 evento "Ciência na rua" é uma criação da professora orientadora e foi desenvolvido em parceria com os discentes colaboradores do projeto de extensão "Estruturação do Acervo Biológico do Laboratório de Zoologia da UENP", em especial a aluna bolsista do subprojeto "Divulgação Científica e Popularização da Ciência no laboratório de Zoologia da UENP/CJ/CCHE". Ambas se dedicaram inteiramente às ações pretendidas pelo evento.

0 evento realizado foi uma das centenas de atividades da Semana Nacional de Ciência e Tecnologia (SNCT). 0 "Ciência na Rua" objetivou a disseminação da ciência na comunidade externa como forma de retornar à sociedade o que é investido por ela na universidade pública. 0 objetivo do evento foi favorecer o contato entre comunidade externa e acadêmica, com o intuito de despertar, nos moradores, interesse pela ciência e, assim, tentar minimizar a escassez de conhecimentos científicos por parte da comunidade externa.

A SNCT foi instituída em 2004 por meio do Decreto de 9 de julho. Na ocasião, o Presidente da República instituiu a comemoração da SNCT no mês outubro, mês nacional da Ciência, Tecnologia e Comunicação. 0 mesmo decreto delibera que as comemorações são coordenadas pelo Ministério da Ciência, Tecnologia, Inovações e Comunicações (MCTIC), com a colaboração de entidades vinculadas ao setor.

A cada ano que se comemora a SNCT, o MCT propõe um tema relevante e atual. No ano de 2018, o tema escolhido foi "Ciências para a redução das desigualdades", relacionado aos Objetivos do Desenvolvimento Sustentável (ODS), especificamente ao tema de número 10. Esse ODS tem o intuito de reduzir a desigualdade dentro dos países e entre eles. 
Os 17 objetivos (ODS) foram traçados pelos chefes de Estado e de Governos, em 2015, com a finalidade de promover os direitos humanos; assim, programou-se a Agenda 2030. Os objetivos definidos visam estimular ações para os próximos anos em áreas de importância crucial para a humanidade e para o planeta (ONU, 2005). É nesse sentido que o "Ciência na Rua” foi pensado e desenvolvido.

0 evento foi realizado na praça, em frente à Universidade Estadual do Norte do Paraná (UENP), conhecida como Ágora, no período das $9 \mathrm{~h}$ às $17 \mathrm{~h}$ do dia 19 de outubro de 2018 (Figura 1). A realização do evento nesse local justifica-se pelo fato de que a praça é um dos pontos favoritos dos moradores da comunidade local e dos estudantes. Assim, de maneira descontraída, foi possível abordar o público sem causar qualquer tipo de estranheza.

Essa demanda social surge a partir da necessidade da popularização da ciência para a comunidade. A universidade atua na cidade há mais de 10 anos. Antes desse período, havia no local uma faculdade, FAFIJA Faculdade Estadual de Filosofia, Ciências e Letras de Jacarezinho-PR, e grande parte da população local ainda é habituada a se referir àquele lugar como faculdade. Poucos sabem das pesquisas científicas desenvolvidas pela Universidade.

0 público-alvo da ação foram os pedestres e estudantes que passavam pelo local, os quais, por motivos diversos, não sabem que dentro da Universidade (UENP) existe um grupo de pesquisadores e de estudantes contribuindo para o desenvolvimento da pesquisa regional. A relevância de propagar essas ações está relacionada, também, ao reconhecimento do grande valor que a instituição promove à ciência, bem como à comunidade.

\section{Figura 1 - Ciência na Rua, realizado na praça}

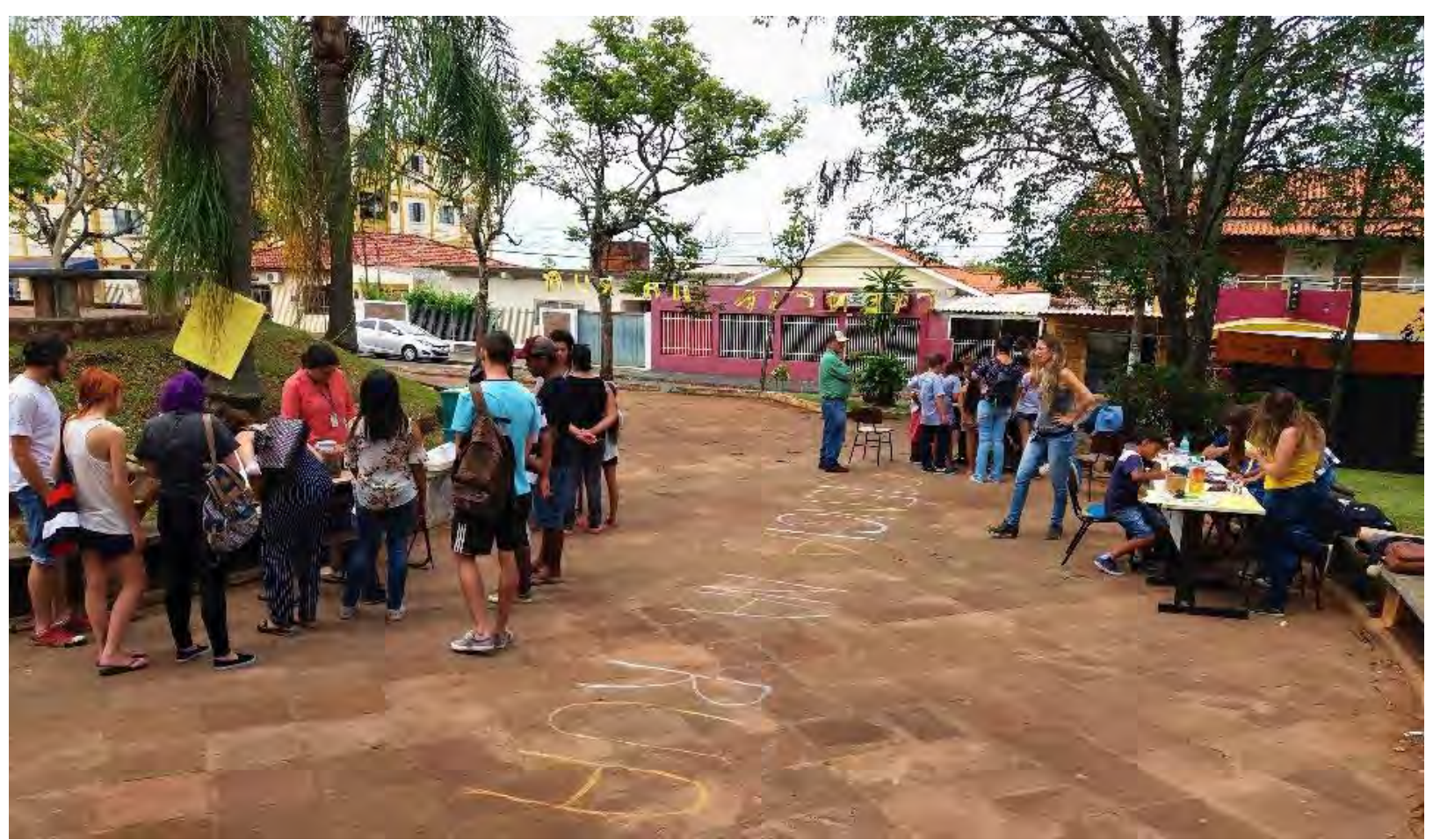

FONTE: Dados desta pesquisa.

0 evento contou com a exposição de animais armazenados em via úmida e em via seca, provenientes da coleção zoológica do laboratório de zoologia. Esse material para fins didáticos é procedente de doações feitas em coletas de projetos de ensino e pesquisas desenvolvidas pelos docentes do curso de Ciências Biológicas. Diferentemente das coleções sistemáticas, que representam grande valor para a ciência e que são normalmente usadas para estudos científicos, as coleções didáticas são aquelas utilizadas em salas de aula para fim didático e que, com o passar do tempo, devido ao desgaste, necessitam de alguns reparos ou substituições (VIVO; SILVEIRA; NASCIMENTO, 2014).

Por sua finalidade, os animais ali presentes estavam disponíveis para observação e manuseio. Para isso, um microscópio estereoscópico esteve à disposição dos visitantes. 0 material exibido permitiu que a comunidade pudesse ter mais contato e aproximação com algumas espécies de animais pouco vistas, como espécies marinhas e animais de importância médica, como escorpiões. 
De forma geral, a atividade despertou grande interesse dos participantes presentes no evento. Além das crianças, que ficaram entusiasmadas com a oportunidade de utilizar pela primeira vez um microscópio, os adultos e idosos demonstraram curiosidade em ver animais sob a lente de aumento (Figura 2).

Um dos exemplares que mais chamou a atenção dos visitantes foi o espécime de escorpião amarelo (Tityus serrulatus LUTZ \& MELLO, 1922), a espécie de maior letalidade do Brasil (TORRES, et al., 2002). A divulgação dos conhecimentos científicos sobre a espécie é de grande importância na região, uma vez que o Paraná apresenta muitos casos de acidentes com escorpiões.

Figura 2 - Observação de animais em microscópio estereoscópio

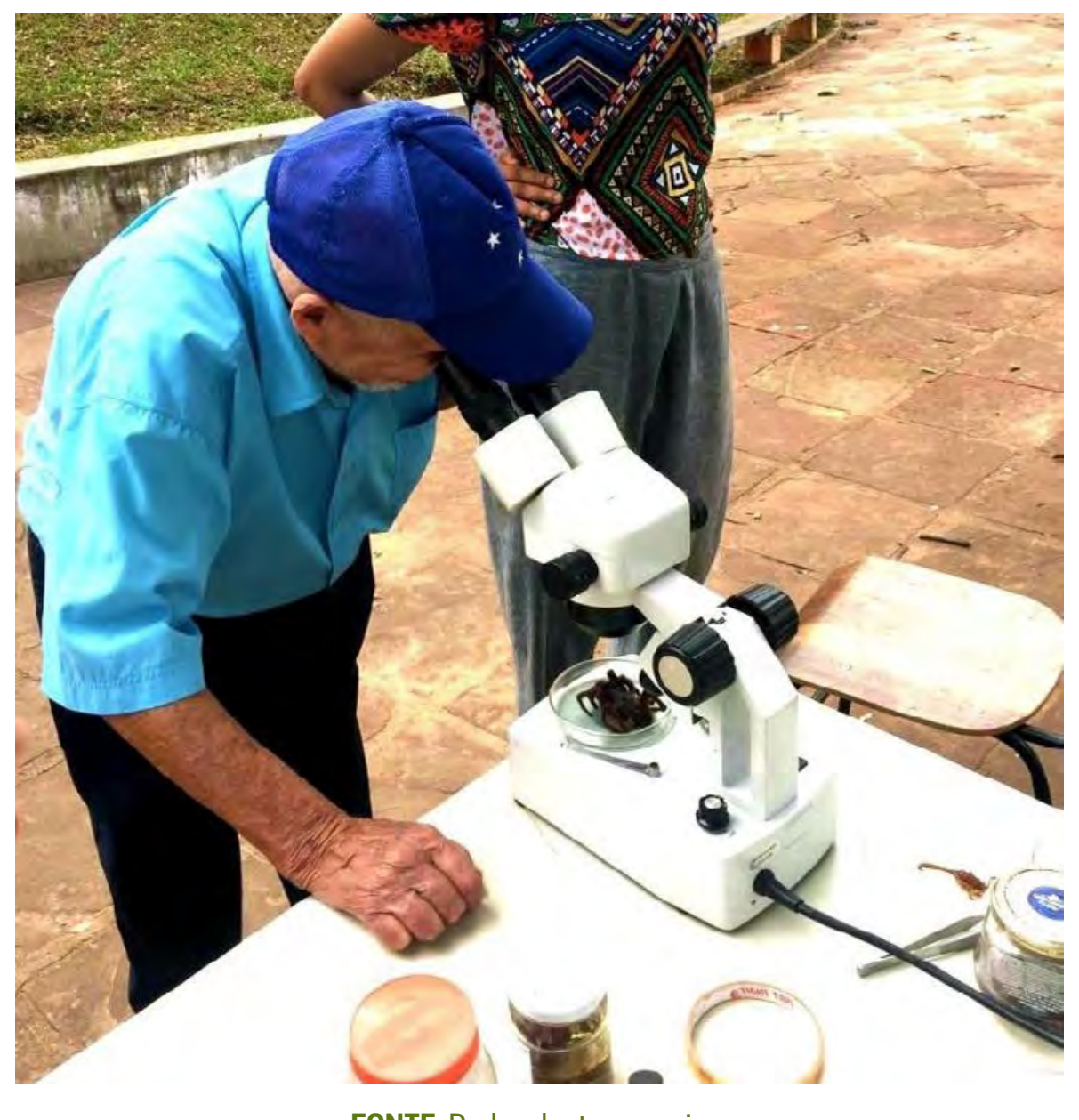

FONTE: Dados desta pesquisa.

Além de participar diretamente na elaboração do evento e nas diferentes atividades realizadas pela ação, a aluna bolsista do projeto elaborou um jogo de sua própria autoria, intitulado "Jogo da Taxonomia". 0 jogo foi desenvolvido durante o evento, com intuito de que os participantes compreendessem a lógica da sistematização tradicional dos organismos. Assim, além de aprimorar o conhecimento sobre os animais apresentados, o jogo permitiu que os participantes obtivessem conhecimentos sobre a taxonomia e sua importância para a ciência.

0 termo taxonomia se origina do grego taxis (ordem) e nomos (lei, norma) e foi usado pela primeira vez em 1735 com a publicação da versão inicial da obra Systema Naturae, pelo cientista e médico sueco Karl Von Linné, e assim [a taxonomia] se tornou conhecida como pertencente ao domínio da biologia. Durante o século XVIII, Linné classificou os seres vivos de acordo com suas características distintivas e os hierarquizou, dividindo-os em Reinos, filos, classes, ordens, famílias, gêneros e espécies, que após algum tempo foram subdivididos. Sua classificação ficou conhecida como "Taxonomia de Lineu” (AGANETTE, ALVARENGA, SOUZA, 2010, p. 78). 
Figura 3 - Aplicação do Jogo da Taxonomia

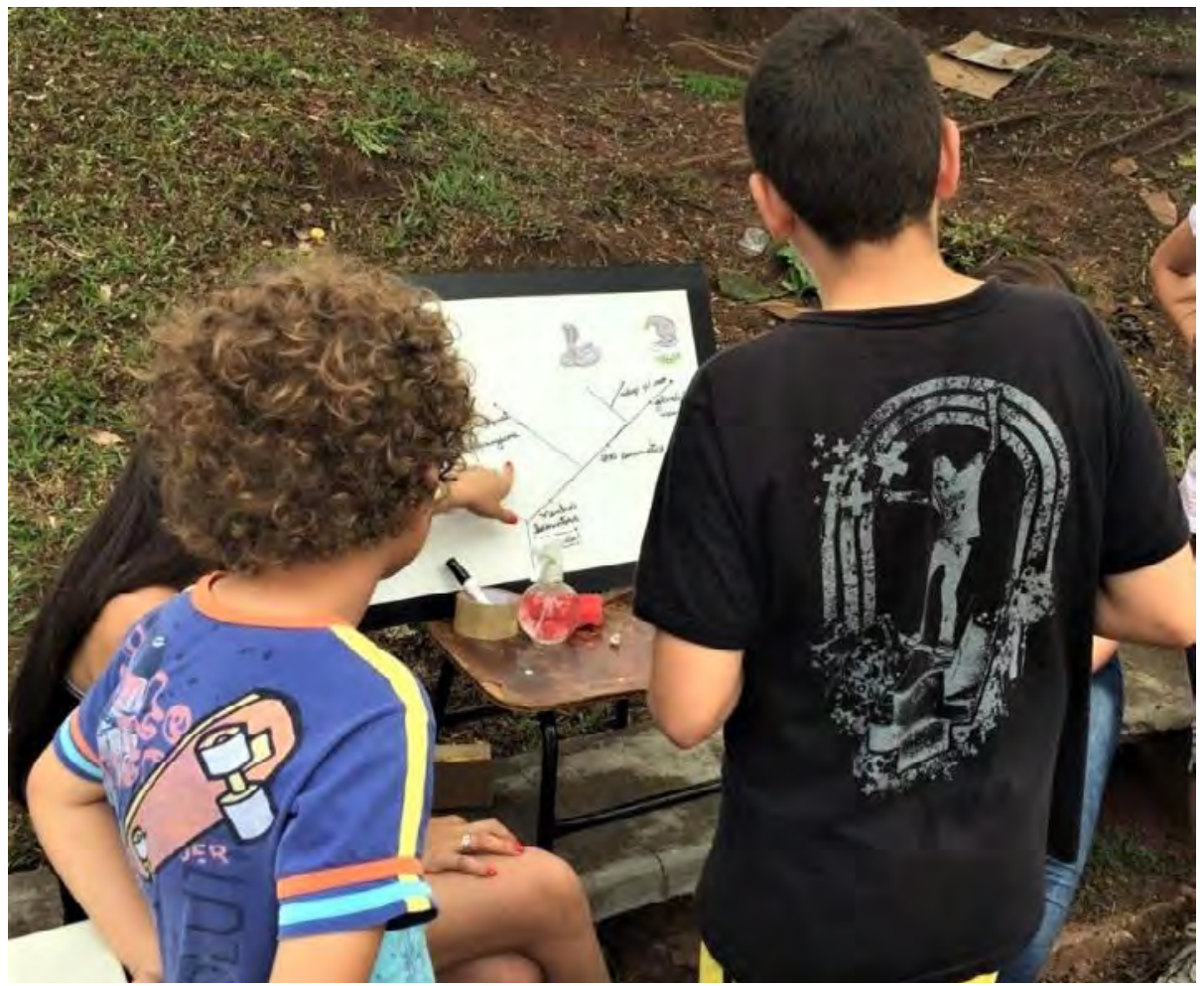

FONTE: Dados desta pesquisa.

Adicionalmente, uma oficina de desenhos foi proposta com o objetivo de entreter e despertar a curiosidade dos participantes sobre a morfologia dos animais disponibilizados. Desse modo, os animais estiveram à disposição para observação das suas principais características, despertando não apenas o interesse pela observação, mas também o interesse em os desenhar.

Sabe-se que o desenho é uma ferramenta muito importante para o desenvolvimento infantil; ele atua como elemento mediador entre o conhecimento e o autoconhecimento daquele que o pratica. A partir do desenho, a criança organiza informações, processa experiências vividas e pensadas, revela seu aprendizado e pode desenvolver um estilo de representação singular do mundo (GOLDBERG; YUNES; FREITAS, 2005, p. 97).

Figura 4 - Oficina de desenho

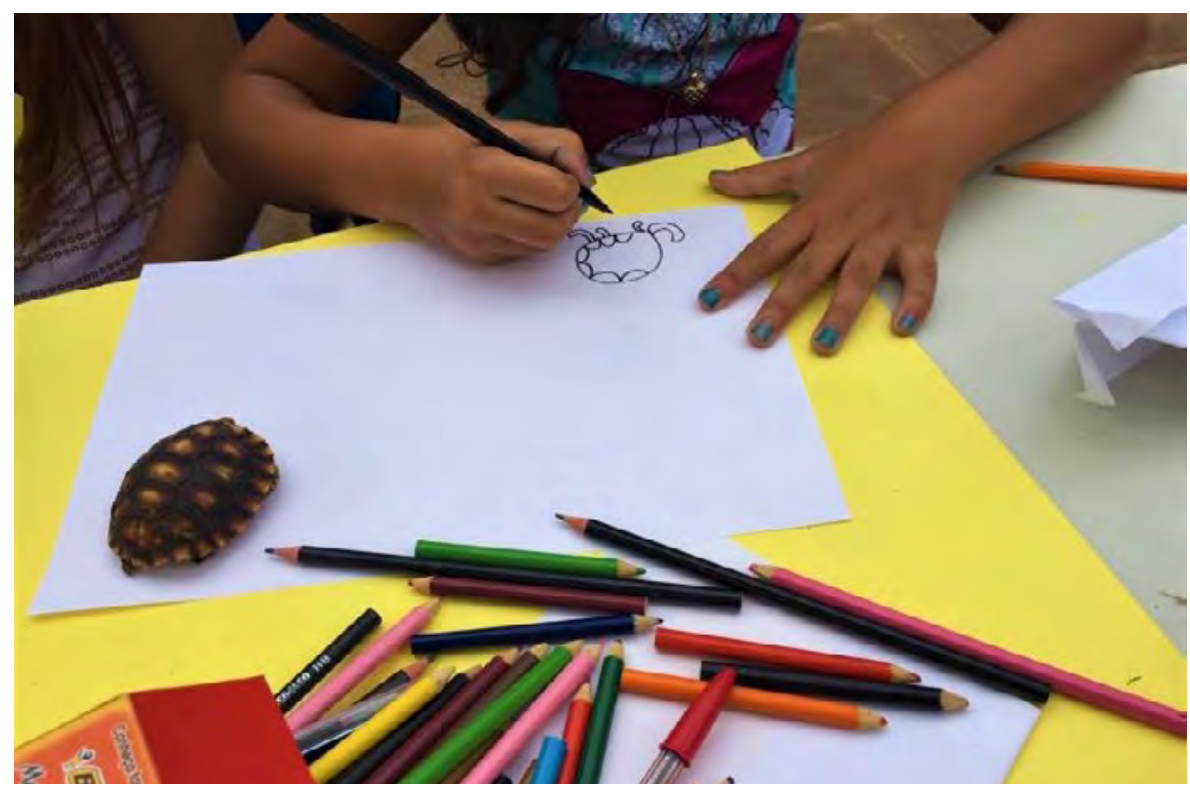

FONTE: Dados desta pesquisa. 
Além das atividades de observação e desenho, uma composteira doméstica também pôde ser observada no evento. Esse tipo de compostagem refere-se a um kit comercial formado por três caixas acopladas que abrigam minhocas, responsáveis pela transformação dos resíduos orgânicos domésticos em humos. Nessa atividade, foi explicada a importância ecológica e econômica dos vermes e da compostagem.

Desde2010, comainstituição daPolíticaNacionalde ResíduosSólidos, Lein¹2.305, aresponsabilidade pelo resíduo gerado é compartilhada, com obrigações que envolvem tanto o poder público quanto o cidadão (BRASIL, 2010). Diante desse cenário, ressalta-se que as ações de sensibilização ambiental são necessárias para a propagação da importância da separação do resíduo doméstico.

Após a realização dessa atividade, chamou a atenção o comentário de um dos participantes. Um senhor de aparentemente 65 anos exclamou, ao final da explanação sobre o processo de compostagem: "Eu não acredito que, com a idade que eu tenho, eu nunca ouvi falar sobre isso". Tal relato se mostrou muito significativo para os organizadores do evento, pois a principal intenção do evento é o compartilhamento do conhecimento científico - muitas vezes restrito à comunidade acadêmica - com a comunidade local da cidade e Jacarezinho, PR.

\section{Figura 5 - Composteira doméstica}

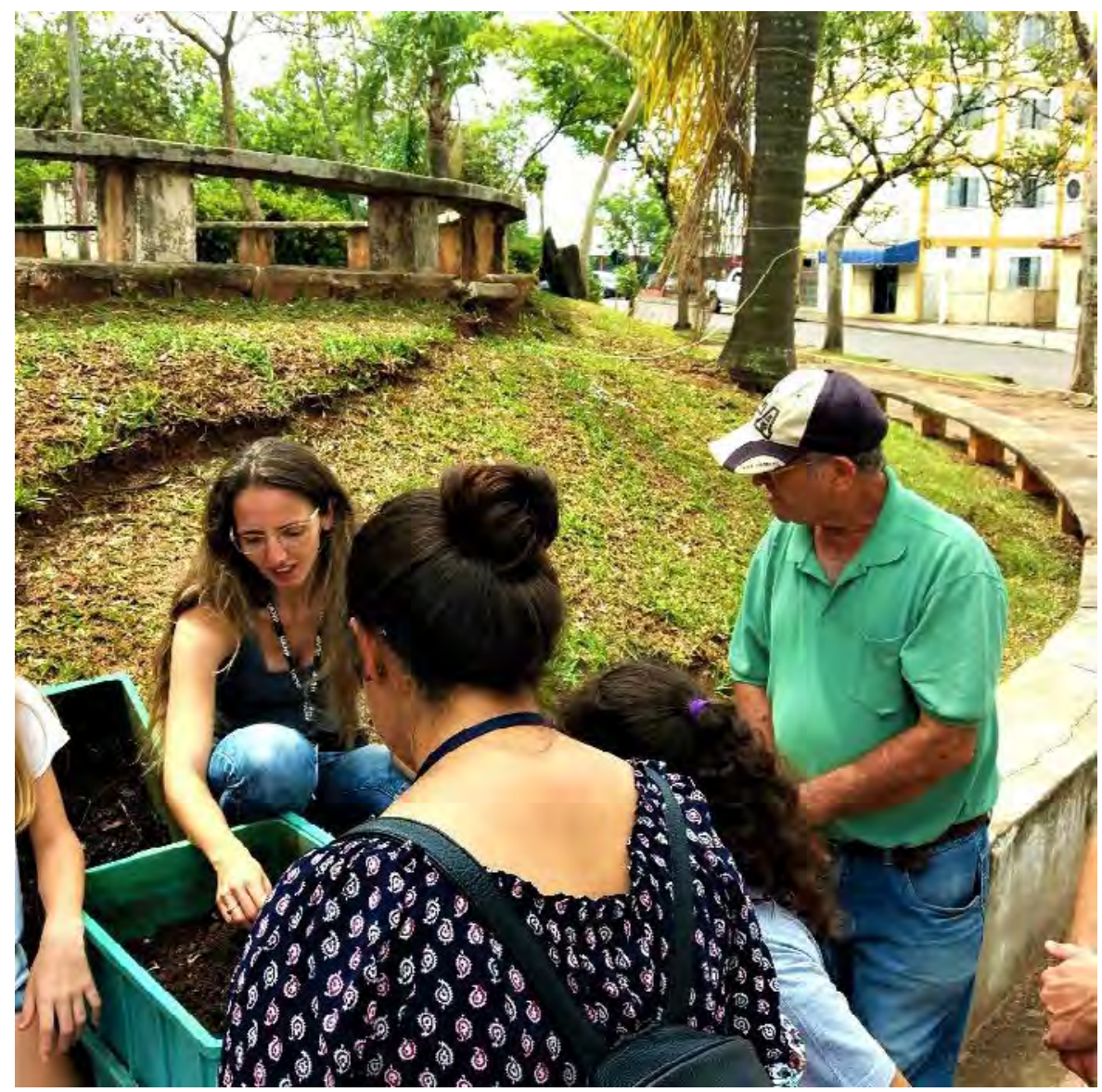

FONTE: Dados desta pesquisa.

A partir das ações relatadas, corroboramos que o ato de divulgar ciência é mecanismo de compartilhamento rápido e barato que permite alcançar todo tipo de público, classe social, idade, gênero e crença. Seguindo essa linha de entendimento, a divulgação científica torna-se uma ferramenta relevante para demonstrar a aplicação prática da ciência no cotidiano; ela possibilita um espaço de interação e de troca de conhecimentos, já que nem todos os indivíduos inseridos na sociedade têm ou tiveram as mesmas oportunidades de acesso aos saberes científicos.

Durante o evento, uma situação curiosa que chamou a atenção dos colaboradores foi a presença de dois meninos, primos de aproximadamente 10 e 12 anos que, ao chegarem ao local, ainda no período da manhã, entre idas e vindas rápidas, mantiveram-se presentes e participando ativamente de todas as atividades oferecidas. Além do mais, diversos foram os momentos em que nos deparamos com expressões como: "Quando eu crescer quero ser professor"; "Eu vou estudar aqui". Tais depoimentos causaram satisfação, haja vista o propósito da ação, que almejou a divulgação da ciência para a socialização dos saberes. 
Ao final das atividades e encerramento do evento, calculamos um público de aproximadamente 100 pessoas, entre crianças, jovens e adultos. Além da comunidade local, passaram pela praça vários outros discentes e alguns professores da Universidade, não relacionados ao curso de Ciências Biológicas. Por vezes, foi observada a presença de grupos de amigos e famílias inteiras comtemplado o evento.

A presença desse público diverso foi algo bastante motivador. A partir da experiência positiva com o "Ciência na Rua", os autores e organizadores pretendem promover outros novos eventos extensionistas. Além disso, assume-se que o evento possa servir de inspiração para outros cursos e universidades, cada um com uma proposta e tema de conhecimento diferente, práticas essas que auxiliariam ainda mais o compartilhamento do conhecimento e a disseminação da ciência em contribuição para a sociedade e formação estudantil.

Assim, concluímos que a ação pontual do "Ciência na Rua" contribuiu positivamente para a divulgação da ciência e do que é produzido por ela. Ademais, favoreceu a aproximação da comunidade externa e acadêmica, além de contribuir para a formação integral dos discentes envolvidos, uma vez que os estudantes puderam expandir o conhecimento adquirido dentro da Universidade para além dela. Além disso, reduzimos a desigualdade existente em relação ao acesso ao conhecimento da população de Jacarezinho-PR.

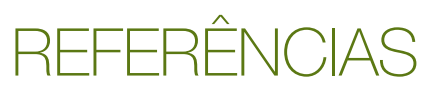

AGANETTE, Elisangela; ALVARENGA, Lídia; SOUZA, Renato Rocha. Elementos Constitutivos do Conceito de Taxonomia. Inf. \& Soc.: Est., João Pessoa, v. 20, n. 3, p.77-93, set./dez. 2010. Disponível em: https://periodicos. ufpb.br/ojs/index.php/ies/article/view/3994/4807. Acesso em: 06 ago. 2020.

BRASIL. Lei de Diretrizes e Bases da Educação Nacional. Lei no 9.394, de 20 de dezembro de 1996. Brasília, 1996. Disponível em: http://www.planalto.gov.br/ccivil_03/Leis/L9394.htm. Acesso em: 12 mai. 2020.

BRASIL. Ministério da Educação. Resolução n. 7, de 18 de dezembro de 2018. Conselho Nacional de Educação. Câmara de Educação Superior. Estabelece as Diretrizes para a Extensão na Educação Superior Brasileira e regimenta o disposto na Meta 12.7 da Lei no 13.005/2014, que aprova o Plano Nacional de Educação - PNE 2014-2024 e dá outras providências. Disponível em: http://portal.mec.gov.br/index.php?option=com_docman \& view $=$ download \& alias=104251-rces007-18 category_slug=dezembro-2018-pdf \& Itemid=30192. Ácesso em: 02 nov. 2020.

BRASIL. Senado Federal. Lei no 12.305, de 2 de agosto de 2010. Institui a Política Nacional de Resíduos Sólidos. Disponível em: http://www.planalto.gov.br/ccivil_03/_ato2007-2010/2010/lei//12305.htm. Acesso em: 30 out. 2020.

Fórum de Pró-Reitores de Extensão das Universidades Públicas Brasileiras. Política Nacional de Extensão Universitária. Manaus: FORPROEX, 2012. Disponível em: https://www.ufmg.br/proex/renex/images/ documentos/2012-07-13-Politica-Nacional-de-Extensao.pdf. Acesso em: 8 abr. 2020.

GOLDBERG, Luciane Germano; YUNES, Maria Angela Mattar; FREITAS, José Vicente de. 0 desenho Infantil na ótica da ecologia do desenvolvimento humano. Psicologia em Estudo, Maringá, v. 10, n. 1, p. 97-106, abr. 2005. Disponível em: https://www.scielo.br/pdf/pe/v10n1/v10n1a11. Acesso em: 18 nov. 2020.

Organização das Nações Unidas. Transformando Nosso Mundo: A Agenda 2030 para o Desenvolvimento Sustentável. 2015. Disponível em: https://nacoesunidas.org/wpcontent/uploads/2015/10/agenda2030-pt-br. pdf. Acesso em 20 nov. 2020.

TORRES, João Batista et al. Acidente por Tityus serrulatus e suas implicações epidemiológicas no Rio Grande do Sul. Rev. Saúde Pública, Viamão, v. 5, n. 36, p.631-633, maio 2002.

VIVO, Mario de; SILVEIRA, Luís Fábio; NASCIMENTO, Fábio Oliveira do. Reflexões sobre coleções zoológicas, sua curadoria e a inserção dos Museus na estrutura universitária brasileira. Arquivos de Zoologia: Museu da Universidade de São Paulo, São Paulo, v. 45, n.esp, p 105-113, 2014. Disponível em: https://www.revistas.usp. br/azmz/article/view/88076/90963. Acesso em: 4 out. 2020. 

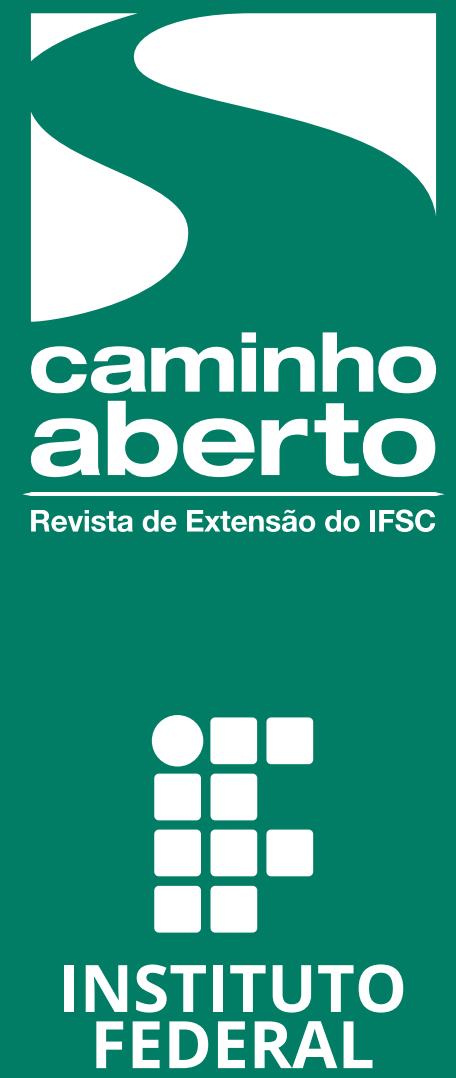

Santa Catarina

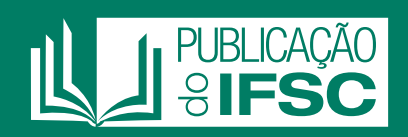

